ACCELERATOR DEPARTMENT
BROOKHAVEN NATIONAI LABORATORY
Associated Universities, Inc.
Upton, I.I., N.Y.

AGS DIVISION TECHNICAL NOTE

\author{
No. 53 \\ F. Pallas \\ June 26, 1968
}

\title{
SLOW EXTERNAL BEAM SEPTUM AND EJECTOR ASSEMBLIES
}

The diverting of a slow external beam from the Alternating Gradient Synchrotron is dependent on the installation of two vacuum box and drawer assemblies installed in the $\mathrm{F}-5$ and $\mathrm{F}-10$ straight sections of the ring.

Both vacuum boxes are weldments fabricated from $1-1 / 2^{\prime \prime}$ thick aluminum alloy 6061 ST6 annealed after welding at $650^{\circ} \mathrm{F}$ for two hours then air cooled. Vacuum testing was performed prior to flat machining and boring of all openings.

The F-5 septum box is 37-7/8 in. in length with an overall height of 17-in. and a depth of 26-5/8 in. Drawer thickness is not included in these dimensions.

The F-10 Ejector Box is 102 inches in length with an overall height of 17 inches and a depth of 26-5/8 inches. Drawer thickness are not included in these dimensions.

Ports of varying diameters are machined into the top, back and sides to accommodate pumpout connections, vacuum interlock for targeting mechanism, beam vacuum pipe connections, viewing ports for television monitoring, thermocouple connections, etc.

The two drawer assemblies contain magnets mounted on a freely sliding plate coupled through two articulated linkages driven by two independent motor drive assemblies which permit lateral movement of the magnets towards, or away from, the accelerated beam within a range of two inches.

The magnet assembly, supporting structure, motar-drive assemblies, electrical and water feed-through are all mounted on a drawer which when closed forms the front face of the vacuum box. Toggle clamps are provided on the box for rapid closing and sealing of the drawer. The drawer is equipped with a roller and rail assembly to permit full opening of the drawer permitting access 
to all internal equipment. Rapid removal of the drawer assembly for servicing and replacement may be accomplished by disconnecting external water and electrical services and lifting the entire assembly off the rail system.

Motor Drive Assemblies

Two drive assemblies consisting of a slo-syn motor, worm and worm wheel, rotate a bronze nut threaded on a captive hollow shaft. Through this shaft, the current carrying bus and water lines are passed for energizing and cooling the magnet. The nut and threaded shaft provide the lateral movement for magnet positioning. The 72 rpm motor with a worm ratio of 15:1 requires an 8 minute interval for a total travel of 2 inches.

Vacuum sealing of the drive shafts is through a stainless steel bellows assembly.

The motor drives are remotely operated from the AGS Control Room. Position Indicator Assemblies

The Septum and Ejector assemblies are provided with two remote reading position indicator assemblies.

An encoder provided with shaft-mounted drum whose circumference is precisely 3.600-in. is driven by a .001-in. stainless steel tape attached to a bellows sealed shaft penetrating into the vacuum box. An insulating probe made from Mykroy fastened to this shaft maintains constant pressure against the magnet and follows any lateral movement. Constant pressure on the probe results from the atmospheric pressure operating on the external bellows floating flange. A Negator motor maintains constant tension on the tape and drum assembly. Total travel of the position indicator is two inches. Remote readout of the magnet position is displayed on a decitrak digital display chassis located in the AGS Control Room. Position accuracy is $\pm 0.001-$ in.

Space limitations on the Septum drawer face necessitated the locating of the two position indicators at the rear of the F-5 box. The indicator probes contact an aluminum angle fastened below the magnet assembly for beam clearance.

The motor drives and position indicator device were darefully calibrated. 
After the magnet was surveyed to a previously determined location with respect to the ring magnet locating socket, See Figure $\#_{1}$ Ejector Assembly and Figure 非 Septum Assembly. The entire vacuum box was sealed and evacuated. The encoder assembly was rotated until a digital display of 0.500 for the Ejector Assembly and 1.500 for the septum Assembly was obtained. The encoder was clamped in this position. This position is called the"neutral" position. Micrometer readings were taken of the flange separations on the Motor Drive Assembly and the Postion Indicator Bellows Assembly. The motor devices were then energized to drive the magnet "towards the beam" for a total distance of 1/2-in. The drives were then utilized to drive the magnet out "from the beam" the total distance af two inches. Micrometer measurements were taken in $1 / 4-$ in. increments. The attached calibration chart records the decitrak readout (Trave1) and compares the corresponding micrometer readout.

The Ejector and Septum Maghnets can be "skewed" by energizing one of the drive assemblies while the other drive remains fixed. Skew limit switches operated by a Differential Bar Assembly restrict the amount of "skew" to protect internal water and electrical connections. The Septum Assembly may be "skemed" a total of 3/16-in. and the Ejector Assembly is limited to 3/8-in. Separate limit switches prevent damage of the drive systems, bellows assemblies and position indicator assemblies. These switches sever the power applied to the Slomsyn motors and are set to trip at each end of the 2-in. range.

\section{Distribution:}

AGS Mechanical Engineers

AGS Operations Coordinators

AGS Administrative Group

AGS Division Heads

M. Barton

L. Blumberg

J. Curtiss

J. Fox

W. Gefiers

W. Glenn

J. Herrara

G. Levine

R. Nawrocky

E. Raka

A. Soukas

T. Toohig 
Flo EJECTOR AsSEMaly

F Pated

\&.

Ninter

Postagn

a.

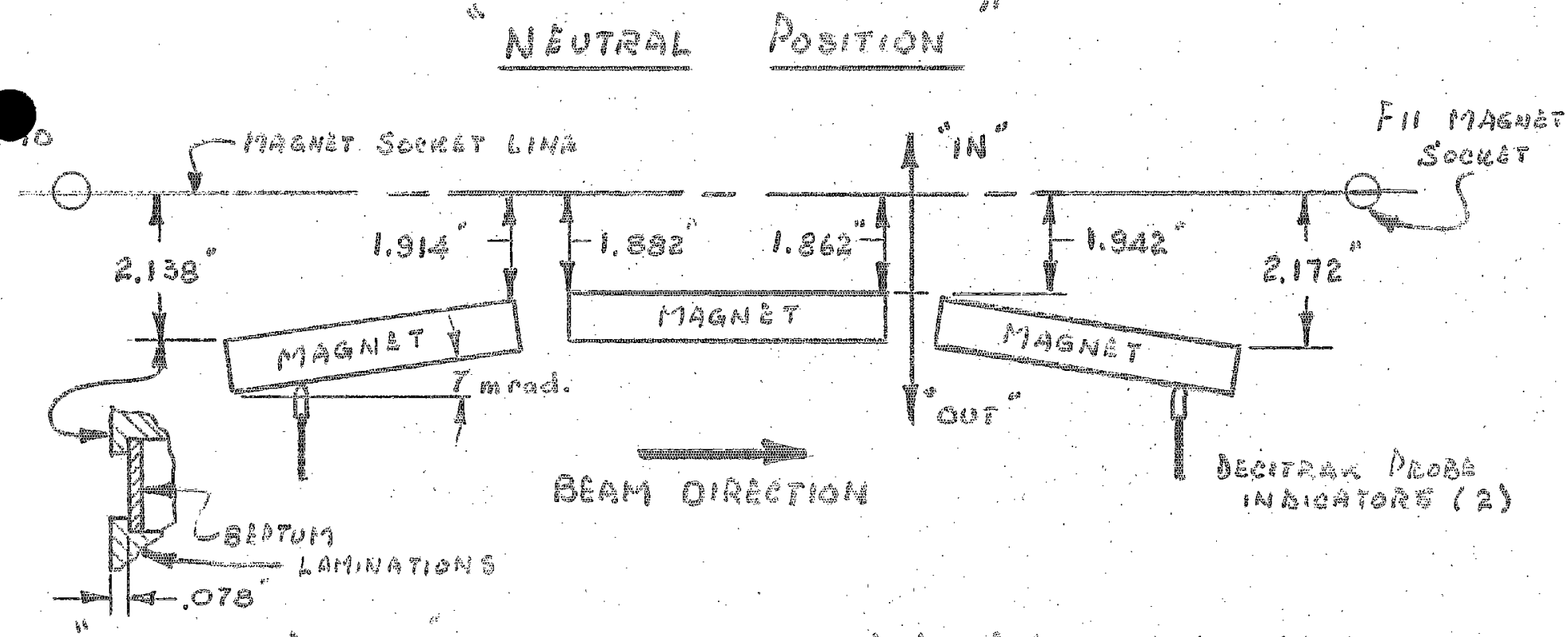

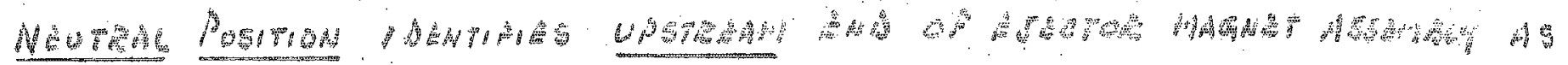

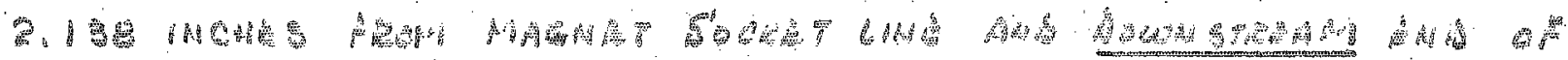

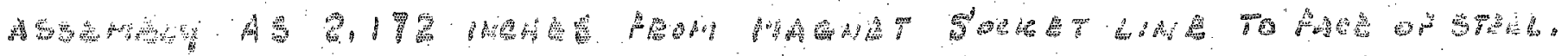

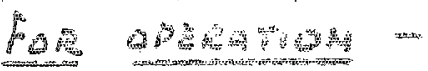

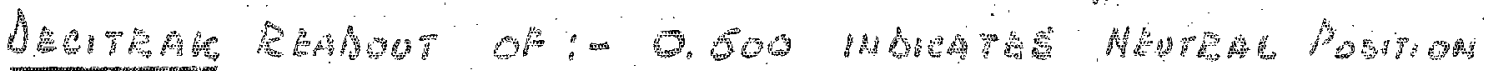

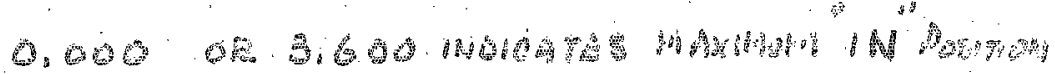

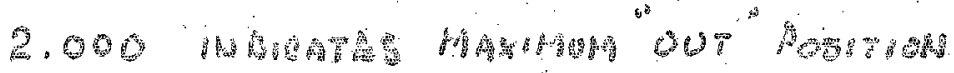

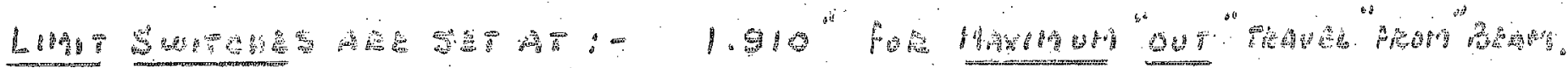

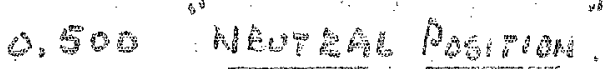

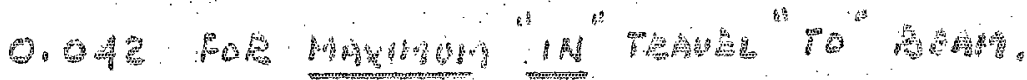

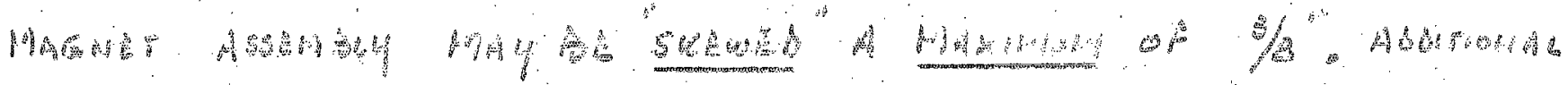

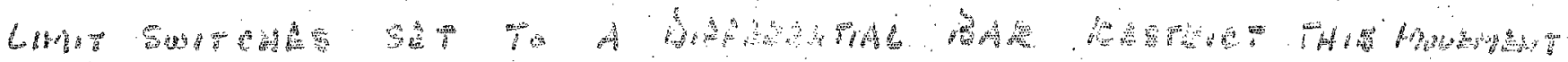

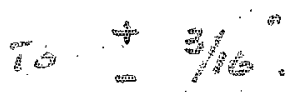

Fig. 1 


\section{F'5 SEPUH ASSMRY}

鹃

NEUPAH POSHION

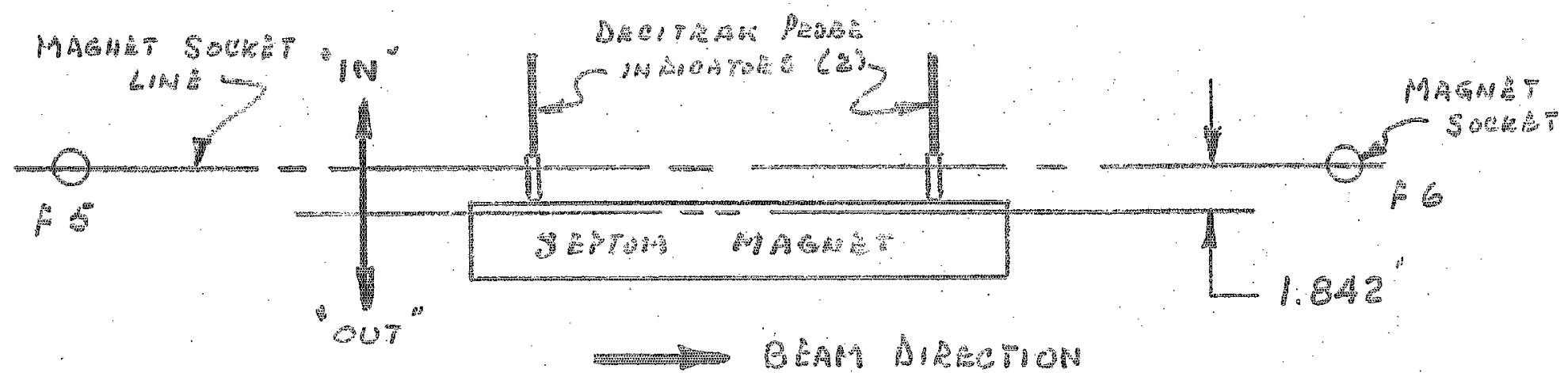

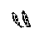

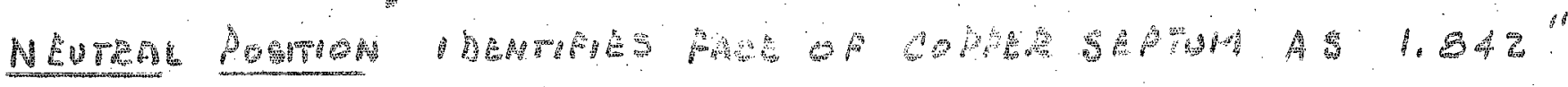

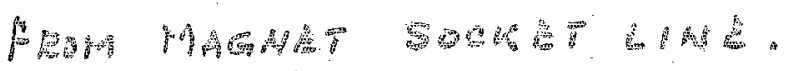

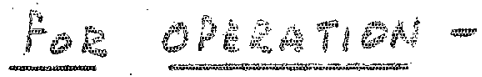

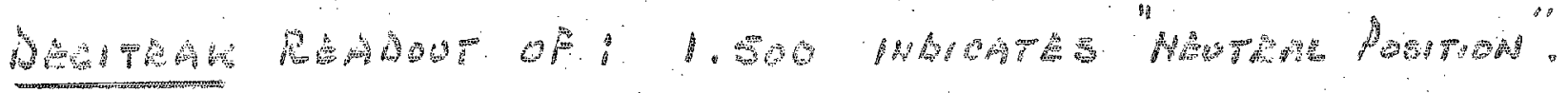

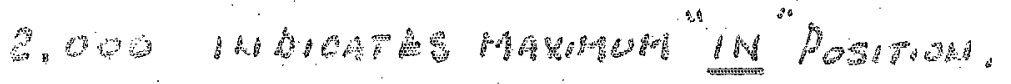

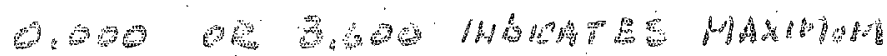

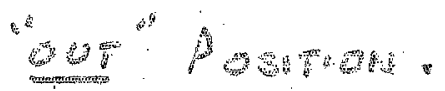

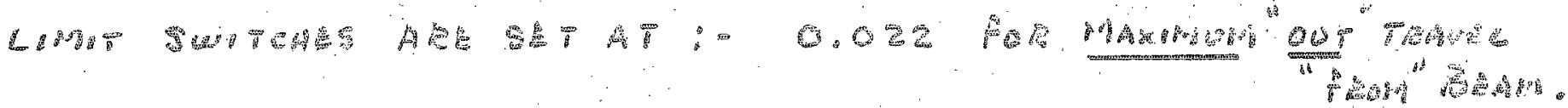

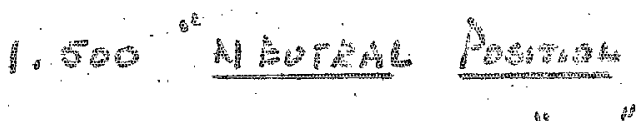

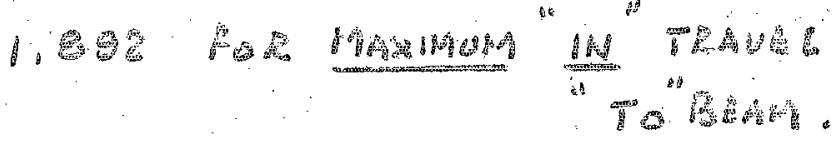

HAGM

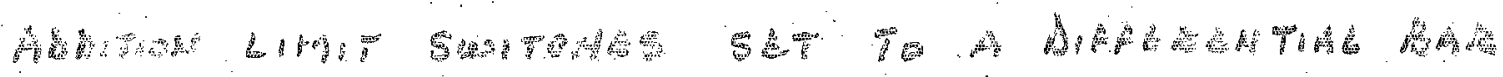

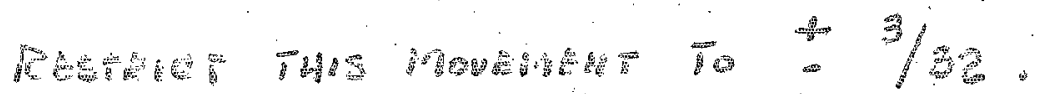


BRDOKHAVEN NATIONAL LABDRATORY

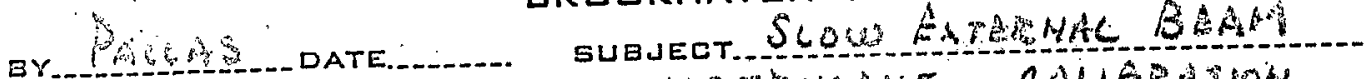

DATE.

INS

CALIBEASYH

(n)

DEPT. QR PROJECT.

MOTOR

DRIVE

ASSEMBLY

(2)

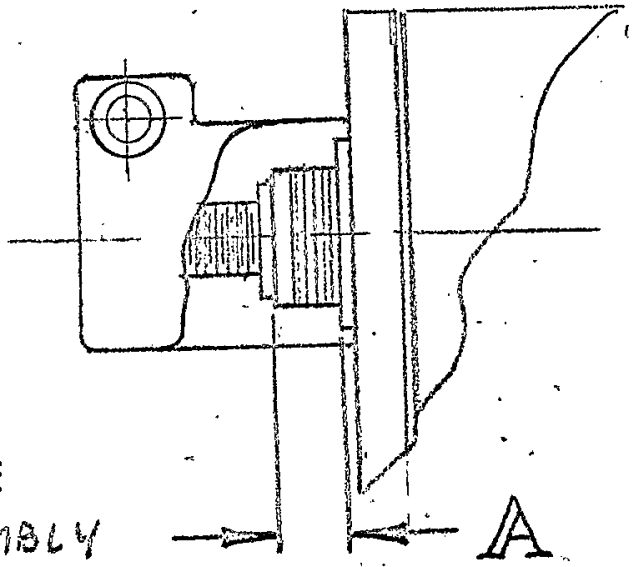

F5

\section{POSITION}

INDICATOR

$A S S \operatorname{sinLY} \rightarrow$

(2)

\begin{tabular}{|c|c|c|c|c|c|}
\hline & $A$ & $B$ & $R A$ & $O N$ & \\
\hline \multicolumn{2}{|c|}{ MOTOR DRIVE ASSY } & \multicolumn{2}{|c|}{ DECITRAK READ. } & \multicolumn{2}{|c|}{ POSINDICATOR } \\
\hline \multicolumn{2}{|c|}{ DIMENSION "AA } & $1 N \in H$ & $\therefore 5$ & \multicolumn{2}{|c|}{ DHENS1ON"BS" } \\
\hline DQWUM STZEAM & UASTREABt & Downstebing & VPSTREAM & Deunstias & 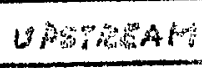 \\
\hline 1.937 & 1.954 & 1.900 & 1.904 & 4.0 .56 & 4.041 \\
\hline 2.098 & 2.109 & 1.750 & 1.746 & 3.901 & 3.903 \\
\hline $2 \cdot 346$ & 2.363 & 1.500 & 1.502 & 3.654 & 3.644 \\
\hline 2.589 & 2.599 & 1.250 & 1.250 & 3.405 & 3.377 \\
\hline 2.857 & 2.859 & 1.000 & 8.000 & 3.152 & 3.142 \\
\hline 3.091 & 3.107 & 0.754 & 0.750 & 2.902 & 2.888 \\
\hline 3.355 & 3.370 & 0.500 & 0.500 & 2.648 & 2.639 \\
\hline \multirow[t]{3}{*}{3.591} & 3.605 & 0.254 & 0.250 & 2. 408 & 2.395 \\
\hline & & & & $=$ & \\
\hline & & & & & \\
\hline
\end{tabular}

TO BEAm

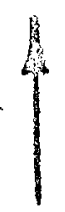

NEGTER

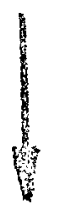

FROM BEAM

CACIBRATED, IS"JUHE 1968

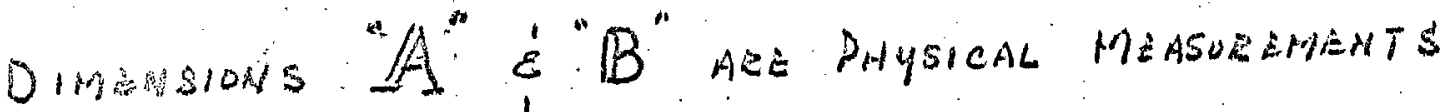
TAKEN WITH AM "INSISE" MICEOMETER.

DESIGH TIEAL TEAUEL = 2 IMCHAS.

Approx. Time Requied $=8$ Muntas

LIMUTS, ARE SET TO TEIP AT:-

Total "SKEW" CIMIT $=3 / 16$."

1.896 DowhSTEAM
1.892 OPSTEATI IN TO

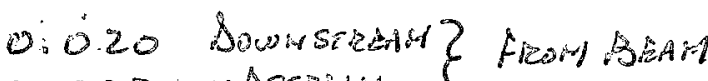


Babas Date.

DATE.

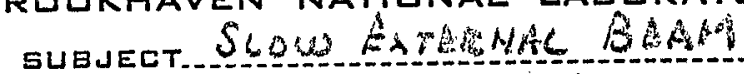

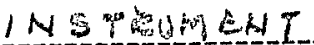

CALIBRAYIOH
SHEET NO Q J日B No
MOTOR DRIVE $A \operatorname{ssch} 64$ (2)

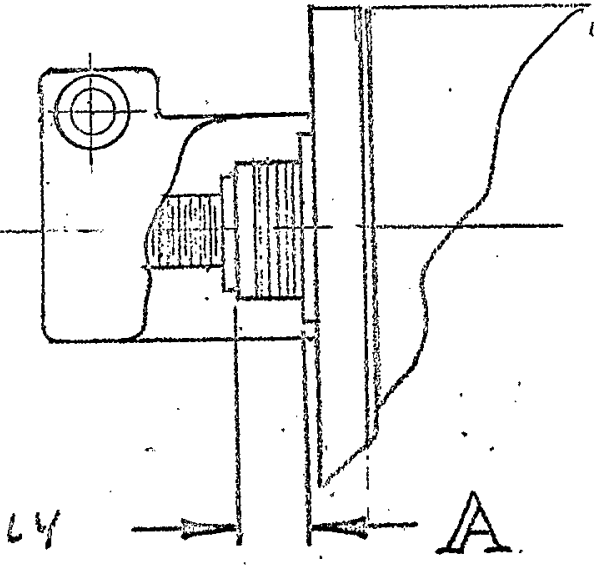

$F 10$

\section{POSITION}

INDICATOR

ASSEMBLY $\rightarrow$ (2)

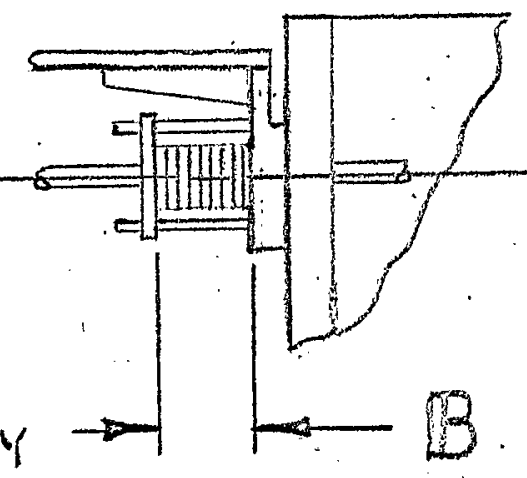

B

EJECTOR \#2

\begin{tabular}{|c|c|c|c|c|c|}
\hline & $\Delta$ & $B$ & $R A T$ & $10 N$ & \\
\hline \multicolumn{2}{|c|}{ MoTOR DRINE ASSY } & \multicolumn{2}{|c|}{ DECITRAK READ. } & \multicolumn{2}{|c|}{ POS.INDICATOR } \\
\hline \multicolumn{2}{|c|}{ DIMENSDON "A" } & \multicolumn{2}{|c|}{$1 N \subset H E S$} & \multicolumn{2}{|c|}{ DMENSIOM "FE" } \\
\hline Down STREAM & UPSTREAM & Bowhoriteris & UPSTREAN & DOWN STRAAAM & UTSTERAB \\
\hline 1.963 & 1.991 & 0.125 & 0.122 & 2.287 & 2.241 \\
\hline 2.098 & 2.126 & 0.250 & 0.253 & 2.413 & 2.368 \\
\hline 2.348 & 2.375 & 0.500 & 0.500 & 2.652 & 2.611 \\
\hline 2.590 & 2.618 & 0.750 & 0.754 & 2.905 & 2.861 \\
\hline 2.837 & 2.863 & 1.000 & 1.000 & 3.114 & 3.156 \\
\hline 3.094 & 3.121 & 1.250 & 1.250 & 3.362 & 3.406 \\
\hline 3.340 & 3.367 & 1.500 & 1.503 & 3.656 & 3.616 \\
\hline 3.596 & 3.621 & 1.751 & 1.750 & 3.900 & 3.864 \\
\hline 3.7 .58 & 3.785 & 1.908 & 1.908 & 4.064 & 4.026 \\
\hline & & - & & & \\
\hline
\end{tabular}

To BEm

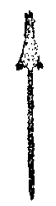

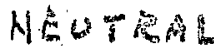

From Bum

Dimensions "Af" ${ }^{\prime} " B$ " $B$ " are physical Mzasuraments TAKEN WITH AM "INSISE" MICZOMETER.

DESIGH TOEAL TEAUEL = 2 IMCHAS.

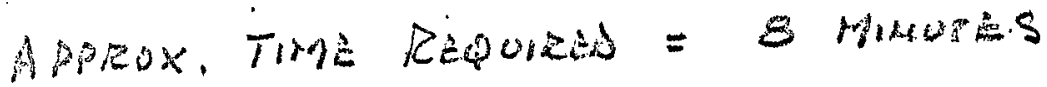
LWOES ARE SET TO TRAD AT 1 Total "SkBw" chmit=3/B

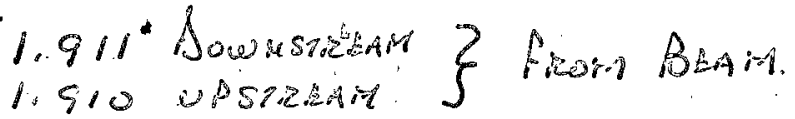
0.045 Downstibar $\}$ To BEAm. 
FIO EJETRR VOUUM BOX 1

\section{UPSTREAM SURVEY INRING}


\$OEIEGTOR VACUUM BO 1

\section{DOWNGTREAM SURVEY NR RNG}

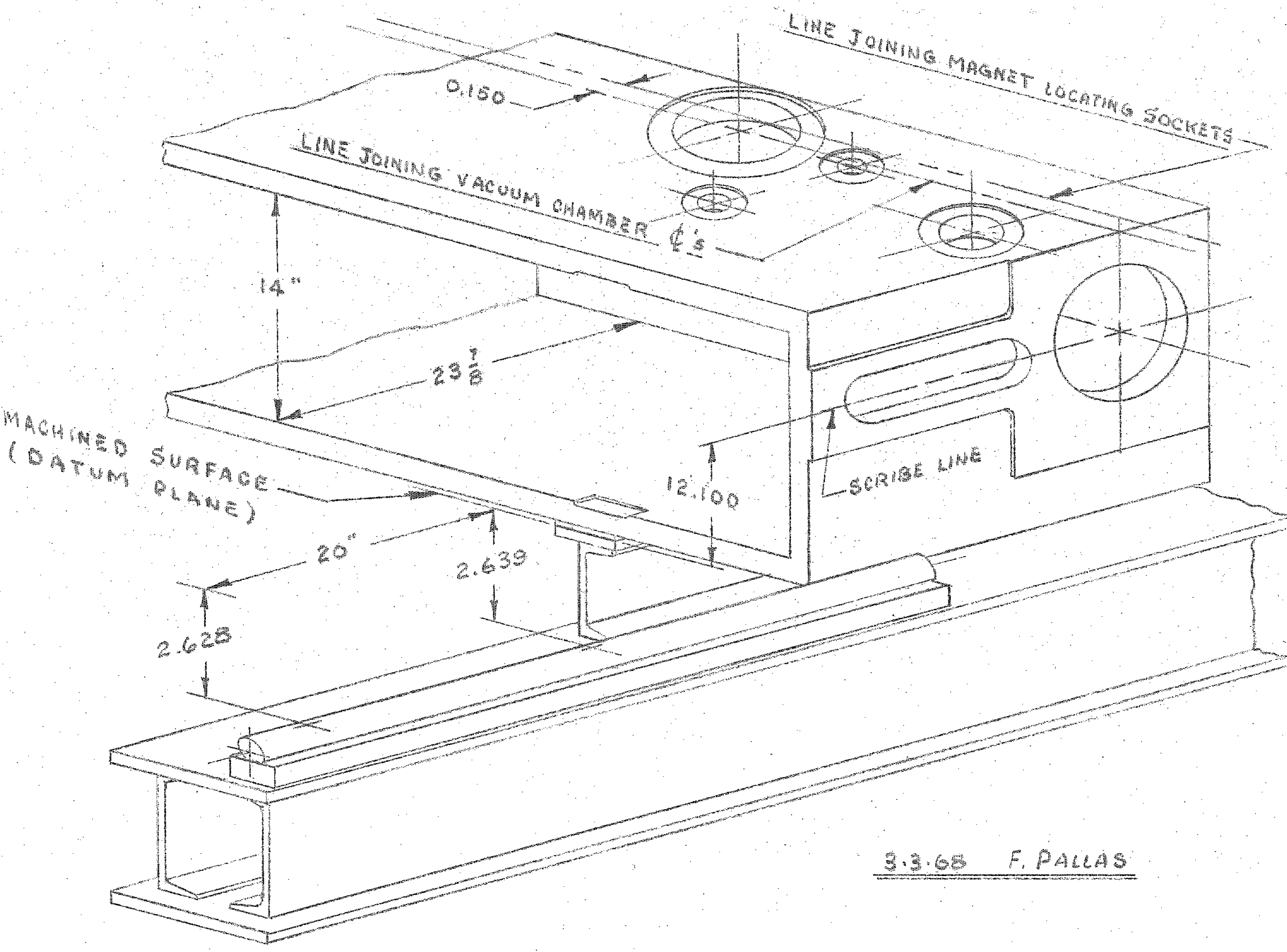




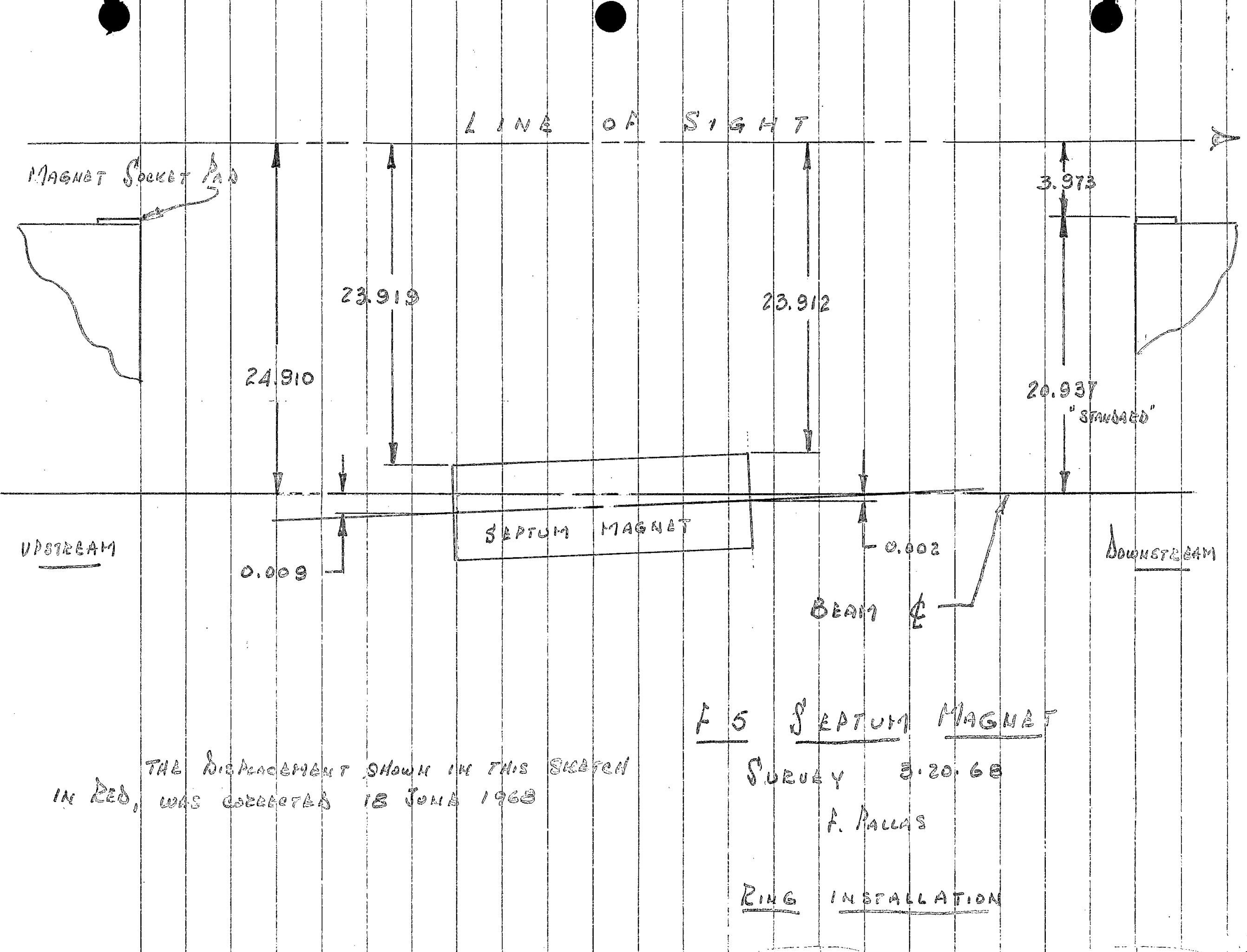


